\title{
Cross-Straitization of Higher Education: Voices of the Mainland Chinese Students Studying in Taiwan
}

\author{
Chuing Prudence Chou and Gregory S. Ching
}

\begin{abstract}
Recent changes in the political atmosphere between Taiwan and Mainland China has led to the lifting of the long-time ban on recruiting Chinese students to study in Taiwan. In September of 2011, more than 900 Chinese students were admitted as degree-seekers to study in Taiwan universities While, the number of short-term exchange programs numbered by the thousands. In light of the current changes from internationalization to cross-straitization; the phenomenal changes in policies that deals with Taiwan and Mainland China, this presentation shall seeks to understand the various push pull factors and implications with regards to the Chinese students studying in Taiwan.
\end{abstract}

Index Terms-Cross-straitization, study abroad, internationalization, study mobility, push-pull theory.

\section{INTRODUCTION}

For the past two decades, Taiwan's higher education institutions have been embracing the concept of internationalization [1], [2]. Until recently the patterns of cross-mobility in Taiwan reflected traditional trends; large numbers of Taiwanese university students studied in the United States (US) and the United Kingdom (UK), while very few incoming international students chose to study in Taiwan. However, in August of 2010, in response to closer cross-strait ties between Taiwan and Mainland China; the government lifted the ban on recruiting Mainland Chinese students [3]. For the first time after the separation of Taiwan and China since 1949, more than 900 Chinese students were admitted as degree-seekers to Taiwan in September of 2011 [4], [5].

The unique model of cross-straitization is prioritizes on cultural and educational exchanges [3]. Within such model, acceptable forms of communication based on mutual respect and understanding are being accomplished. More importantly, cross-straitization is a channel to facilitate Taiwan's sustainable coexistence with China and the rest of the world [6].

Within the cross-straitization of Taiwan higher education (the opening up of Taiwan universities for mainland Chinese students), many rules and regulations are imposed which

Manuscript received January 13, 2014; revised March 15, 2014. This work was supported in part by the Taiwan National Science Council under Grant numbers 102-2410-H-262-012-SS2 and 102-2410-H-004-206-MY2.

C. P. Chou is with the Department of Education, National ChengChi University, Wenshan District, Taipei City 116, Taiwan (e-mail: iaezcpc2007@gmail.com).

G. S. Ching is with the Graduate School of Educational Leadership and Development, Fu Jen Catholic University, Xinzhuang District, New Taipei City 24205, Taiwan (e-mail: gregory_ching@yahoo.com). seems to create a barrier in attracting Chinese students.

Such as: a.) Once their student identity is forfeited, they must leave the country within 10 days; b.) Once their studies are completed, they must leave within a month of graduation; and c.) Students cannot study in classes, majors, or fields related to national security, just to name a few [7].

In the US, the number of mainland Chinese students enrolled in US universities is currently at an all-time high [8]. However, in Taiwan the number of Chinese students studying degree programs is much lower than the expected 2000 quota. In a recent statistics, Kuo [9] reported that around $20 \%$ of the 56,000 international students in Taiwan are mainland Chinese students who are on short term studies. Private schools were unsatisfied with this number, saying that there are simply too many legal restrictions. Currently, the number of mainland Chinese students in Taiwan is limited only to $2 \%$ of a university's total enrollment. While, public (national) universities are only permitted to accept graduate students [5]. The entity of Taiwan universities as both the mediators and reactors of the mainland Chinese students is a critical area of debate and investigation. Yet to date empirical studies examining factors within the Taiwan context are limited.

In light of the current changes from internationalization to cross-straitization (the changes in policies that deal with Taiwan and mainland China), this presentation shall seek to understand the various pull factors and implications with regards to the mainland Chinese students in Taiwan. It is noted that study abroad opens up opportunity to various insights and built-up necessary skills to interact with people who are different. More so, with the current emphasis on doing businesses in China, understanding how mainland Chinese students react in a new environment is a step towards better future cooperation. Lastly, it is understood that educational institutions provides the venue for study abroad that are quite important for opening up a range of opportunities in achieving social and economic mobility, securing employment, and developing future life skills.

\section{A. Research Questions}

With a primary objective of understanding the mainland Chinese students' perceived study experiences in Taiwan, initial research questions are generated as follows:

- What are the basic demographical backgrounds of the students?

- What are the differences in comparison to their home?

- What are the students' acculturation difficulties?

- What are the students' study experiences?

- What are the students' push-pull factors in study abroad? 


\section{THEORETICAL FRAMEWORK}

Internationalization; more specifically in the East Asian sector, has become a major drive force by most higher education systems in the region [10]. Recent policy initiatives dedicated to expanding the cross border mobility of both inbound and outbound students have been established being established. These initiatives have actually changed into the inter-regional exchanges as compared to the previous international ones.

Within the student mobility issues, a major research theory is identified with the push-pull framework [2], [11]-[16]. Suggesting that international students goes through a series of developmental stages of decision making, which starts from the commitments to study internationally and ending with the selection of host institutions. More specifically, push factors are defined as the conditions in home nations that engender interest in university education beyond national borders. While, the Pull factors are said to be the how a host country could attract international students in studying at a particular university [17].

In a study by Roberts et al. [16] shows that the typical pull factors for international students in Taiwan are mostly related to the scholarship availability and together with the opportunity to study in a Mandarin Chinese language program provided to the students. Furthermore, in a wider follow-up study, Chou et al. [2] uses a revised version of the survey by Roberts et al. [16] resulted in tabulating the major pull factor as the word of mouth recommendations made by the international students' friends. Such result notes that when an international student is exposed to positive experiences, these experiences can be later translated into free advertisement. However, with the current issues for the mainland Chinese students; the study seeks to determine if whether the previous results from the international students' perception will also be true for the Chinese students.

In sum, the utility of the push-pull framework defined international students as a homogenized group rather than as clusters of individuals who have significant differences between and within their nationalities, hence, within the notion of cross-straitization; wherein the students are also of the same Chinese ethnicity, results should open up new variations within the paradigm.

\section{RESEARCH METHODOLOGY}

\section{A. Research Design}

This study employed the descriptive research paradigm; a qualitative research that is concerned with how something that exists is related to some preceding event that has influenced or affected a present condition or event [18].

\section{B. Participants and Research Process}

The survey was done in two folds, $1^{\text {st }}$ phase is for the short-term mainland Chinese students (students who are in Taiwan for only a semester to a maximum of 1 year) and $2^{\text {nd }}$ phase for the degree seeking mainland Chinese students. A revised version of the Chou et al. [2] survey was distributed to all the mainland Chinese students starting September 2011 until February 2012. A total of 415 valid respondents for the short-term mainland Chinese students and a total of 395 valid respondents for the degree seeking mainland Chinese students was collected and analyzed. Besides the demographic information asked, the survey consists of the following sections: study goals, study experiences, perceived characteristics of Taiwanese people, and personal reactions (open ended). Cronbach validity for the $1^{\text {st }}$ phase is .95 and .90 for the $2^{\text {nd }}$ phase, which are considered quite reliable [19], [20].

\section{RESUlTS AND DisCUSSIONS}

\section{A. Demographical Backgrounds of the Chinese Students}

Table I shows the various demographical backgrounds of the participants. Within both degree seeking and short-term study program students; the number of female students is much higher than their male counterparts. As for the courses of study, Business and Management Courses still ranks the highest with around $27 \%$ of the 810 total participants. This is followed by Engineering Courses with $17 \%$ and Law, Languages, and Broadcast Media with 16\%. For the level of study, as expected more graduate students are enrolled in a degree seeking program, while short-term study program involves more undergraduate students.

TABLE I: DEMOGRAPHICAL BACKGROUND OF THE STUDENTS $(N=810)$

\begin{tabular}{|c|c|c|c|c|c|c|}
\hline \multirow{2}{*}{ Items } & \multicolumn{2}{|c|}{ Degree } & \multicolumn{2}{|c|}{ Short term } & \multicolumn{2}{|c|}{ Total } \\
\hline & $n$ & $\%$ & $n$ & $\%$ & $n$ & $\%$ \\
\hline \multicolumn{7}{|l|}{ Gender } \\
\hline Female & 203 & 25.10 & 272 & 33.60 & 475 & 58.60 \\
\hline Male & 192 & 23.70 & 143 & 17.70 & 335 & 41.40 \\
\hline TOTAL & 395 & 48.80 & 415 & 51.30 & 810 & $\begin{array}{c}100.0 \\
0\end{array}$ \\
\hline \multicolumn{7}{|l|}{ Course } \\
\hline Business and Management & 112 & 13.80 & 105 & 13.00 & 217 & 26.80 \\
\hline Law, Languages, \& Media & 69 & 8.50 & 63 & 7.80 & 132 & 16.30 \\
\hline Engineering & 54 & 6.70 & 83 & 10.20 & 137 & 16.90 \\
\hline Humanities and Tourism & 47 & 5.80 & 73 & 9.00 & 120 & 14.80 \\
\hline Arts and Design & 45 & 5.60 & 24 & 3.00 & 69 & 8.50 \\
\hline Computer Sciences and IT & 28 & 3.50 & 29 & 3.60 & 57 & 7.00 \\
\hline Health and Medicine & 25 & 3.10 & 21 & 2.60 & 46 & 5.70 \\
\hline Natural Sciences & 13 & 1.60 & 13 & 1.60 & 26 & 3.20 \\
\hline Education & 2 & 0.20 & 4 & 0.50 & 6 & 0.70 \\
\hline \multicolumn{7}{|l|}{ Level } \\
\hline Undergraduate & 298 & 36.80 & 366 & 45.20 & 664 & 82.00 \\
\hline Master & 88 & 10.90 & 45 & 5.60 & 133 & 16.40 \\
\hline $\mathrm{PhD}$ & 9 & 1.10 & 4 & 0.50 & 13 & 1.60 \\
\hline \multicolumn{7}{|l|}{ Source China school type } \\
\hline Public (National) & 184 & 22.70 & 267 & 33.00 & 451 & 55.70 \\
\hline Public (Regional) & 114 & 14.10 & 76 & 9.40 & 190 & 23.50 \\
\hline Public Technical/Vocational & 10 & 1.20 & 19 & 2.30 & 29 & 3.60 \\
\hline Private & 82 & 10.10 & 47 & 5.80 & 129 & 15.90 \\
\hline $\begin{array}{c}\text { Private } \\
\text { Technical/Vocational }\end{array}$ & 5 & 0.60 & 6 & 0.70 & 11 & 1.40 \\
\hline
\end{tabular}

TABLE II: MAJOR SOURCE LOCATION OF CHINESE STUDENTS $(N=810)$

\begin{tabular}{ccccccc}
\hline \hline \multirow{2}{*}{ Items } & \multicolumn{2}{c}{ Degree } & \multicolumn{2}{c}{ Short term } & \multicolumn{2}{c}{ Total } \\
\cline { 2 - 7 } & $n$ & $\%$ & $n$ & $\%$ & $n$ & $\%$ \\
\hline Fujian Province & 105 & 13.00 & 28 & 3.50 & 133 & 16.40 \\
Zhejiang Province & 76 & 9.40 & 49 & 6.00 & 125 & 15.40 \\
Guangdong Province & 71 & 8.80 & 56 & 6.90 & 127 & 15.70 \\
Beijing City & 41 & 5.10 & 8 & 1.00 & 49 & 6.00 \\
Shanghai City & 37 & 4.60 & 6 & 0.70 & 43 & 5.30 \\
Jiangsu Province & 32 & 4.00 & 18 & 2.20 & 50 & 6.20 \\
\hline \hline
\end{tabular}

As for the major source locations of the Mainland Chinese students, Table II shows that Fujian province ranks the highest due to its close similarity to the local Taiwanese 
people (Southern Min people). In addition, the duration of the short-term students' stay in Taiwan was also noted in Table III. Table III shows that most exchange students stays for 1 semester.

TABLE III: SHORT-TERM STUDY ABROAD STUDENTS $(N=415)$

\begin{tabular}{ccc}
\hline \hline \multirow{2}{*}{ Durations } & \multicolumn{2}{c}{ Short term } \\
\cline { 2 - 3 } & $n$ & $\%$ \\
\hline 1 year & 7 & 1.69 \\
1 semester & 312 & 75.18 \\
4 months & 93 & 22.41 \\
3 months & 3 & 0.72 \\
\hline \hline
\end{tabular}

\section{B. Comparative Differences from Studying in Taiwan}

For the comparative differences among the study experiences between the time their at home and in Taiwan, students were asked regarding their comments regarding the source of school information and their monthly expenditures. Table 4 states that students would actively check the websites of Taiwan universities. This is quite useful since most websites are quite extensively maintained. However, as compared to previous studies with international students (non-Chinese speaking); results in previous studies show that the English websites of Taiwan universities needs to be updated and maintained [21]. This clearly indicates a difference that is of importance.

For their choice host institutions, most mainland Chinese students would look into the websites of Taiwan universities and then decides which university to go to. It is quite interesting that some of the degree seeking students, tends to rely on other websites and internet resources (such as: discussion forums) for information.

Besides the websites, students who participated in the short-term exchange programs would get their information from their schools. In addition, to a surprise student also gets information from their parents. As later compared with the major source of financial supports, which is from their parents (shown in Table V). Results are justifiable, since the parents are the major source of support, they are quite concern to where their children will study.

TABLE IV: MAJOR SOURCE OF INFORMATION FOR SCHOOL CHOICE $(N=810)$

\begin{tabular}{|c|c|c|c|c|c|c|}
\hline \multirow{2}{*}{ Items } & \multicolumn{2}{|c|}{ Degree } & \multicolumn{2}{|c|}{ Short term } & \multicolumn{2}{|c|}{ Total } \\
\hline & $n$ & $\%$ & $n$ & $\%$ & $n$ & $\%$ \\
\hline $\begin{array}{c}\text { Taiwan universities' } \\
\text { websites }\end{array}$ & 326 & 40 & 197 & 24 & 523 & 64.57 \\
\hline Parents & 77 & 10 & 180 & 22 & 257 & 31.73 \\
\hline School's website and bulletin & 67 & 8 & 170 & 21 & 237 & 29.26 \\
\hline Teachers recommendation & 47 & 6 & 81 & 10 & 128 & 15.80 \\
\hline Classmates and friends & 40 & 5 & 67 & 8 & 107 & 13.21 \\
\hline
\end{tabular}

TABLE V: MAJOR SOURCE OF FINANCIAL SUPPORT $(N=810)$

\begin{tabular}{|c|c|c|c|c|c|c|}
\hline \multirow{2}{*}{ Items } & \multicolumn{2}{|c|}{ Degree } & \multicolumn{2}{|c|}{ Short term } & \multicolumn{2}{|c|}{ Total } \\
\hline & $n$ & $\%$ & $n$ & $\%$ & $n$ & $\%$ \\
\hline Parents & 314 & 38.77 & 407 & 50.25 & 721 & 89.01 \\
\hline $\begin{array}{l}\text { Mainland China's } \\
\text { scholarship }\end{array}$ & 2 & 0.25 & 53 & 6.54 & 55 & 6.79 \\
\hline Personal savings & 59 & 7.28 & 40 & 4.94 & 99 & 12.22 \\
\hline $\begin{array}{c}\text { Taiwan's scholarship } \\
\text { Others }\end{array}$ & & & 10 & 1.23 & 10 & 1.23 \\
\hline Internship & & & 3 & 0.37 & 3 & 0.37 \\
\hline Alumni scholarship & & & 1 & 0.12 & 1 & 0.12 \\
\hline Teachers support & 3 & 0.37 & 1 & 0.12 & 4 & 0.49 \\
\hline
\end{tabular}

When asked regarding their perceived monthly expenditures, Table VI shows that most students mentioned their expenses are just similar to that of their home country. Result indicates that this pull factor is not that enticing as compared to the notion of affordable livelihood while studying.

\begin{tabular}{ccccccc} 
TABLE VI: COMPARISON OF MONTHLY EXPENDITURES $(N=810)$ \\
\hline \hline \multirow{2}{*}{ Items } & \multicolumn{2}{c}{ Degree } & \multicolumn{2}{c}{ Short term } & \multicolumn{2}{c}{ Total } \\
\cline { 2 - 7 } & $n$ & $\%$ & $n$ & $\%$ & $n$ & $\%$ \\
\hline Higher than China & 125 & 15.43 & 185 & 22.84 & 310 & 38.27 \\
Similar with China & $\mathbf{2 2 8}$ & 28.15 & $\mathbf{2 1 7}$ & 26.79 & 445 & 54.94 \\
Lower than China & 29 & 3.58 & 13 & 1.60 & 42 & 5.19 \\
\hline \hline
\end{tabular}

\section{Acculturation Difficulties}

With regards to the difficulties and problems faced before and after studying in Taiwan, Table VII and VIII shows the breakdown of the major results gathered from the degree seeking students. The top difficulties as mentioned by the students are namely: getting accustomed to the Local Taiwanese dialect, Transportation - getting around Taiwan, Political atmosphere, Home sickness, Cultural differences, Weather - getting accustomed to the weather, Taiwanese society in general - how people go about with their life, and Food. In addition, besides the strict requirements in Mainland China; individual VISA applications for degree seeking students are the main barrier to smooth study abroad application.

TABLE VII: PROBLEMS TO ACCULTURATION $(N=395)$

\begin{tabular}{ccc}
\hline & \multicolumn{2}{c}{ Degree seeking } \\
\hline \hline Factors & $n$ & $\%$ \\
\cline { 2 - 3 } Local Taiwanese dialect & 139 & 35.19 \\
Transportation & 113 & 28.61 \\
Political atmosphere & 87 & 22.03 \\
Home sick & 85 & 21.52 \\
Cultural differences & 79 & 20.00 \\
Weather & 76 & 19.24 \\
Faiwanese society in general & 75 & 18.99 \\
Food & 69 & 17.47 \\
Traditional Chinese characters & 40 & 10.13 \\
Way of living (lifestyle) & 38 & 9.62 \\
Teaching and learning process & 35 & 8.86 \\
Parents high expectation & 29 & 7.34 \\
School policies & 26 & 6.58 \\
Lack of information on courses of study & 6 & 2.28 \\
\hline \hline Teacher student relationship & 9 & 1.01 \\
\hline \hline
\end{tabular}

\section{Study Experiences}

In the section regarding the mainland Chinese students' study goals, Table IX shows that the short-term exchange 
students agrees that their main reason for coming to Taiwan is to experience a culture different from their own with $93 \%$. This is then followed by experience local Taiwanese culture with $90 \%$, increased learning experiences with $73 \%$, and increased personal competencies with $68 \%$.

With regards to the students' study experiences, major issues being discussed with local Taiwanese students are issues regarding curriculum program and studies (61\% short-term students, 65\% - degree seeking students) and places to visit in Taiwan (85\% - short-term students, 55\% degree seeking students). Further implications are also provided on the various perceptions provided by the mainland Chinese students (as shown in Tables X to XIII).

TABLE IX: REASONS FOR STUDYING IN TAIWAN $(N=415)$

\begin{tabular}{ccc} 
& \multicolumn{2}{c}{ Short-term } \\
\cline { 2 - 3 } Factors & $n$ & $\%$ \\
\hline Broaden my viewpoints/new experiences & $\mathbf{3 8 4}$ & 92.53 \\
Experience local Taiwanese culture & 375 & 90.36 \\
Increased learning experiences & 302 & 72.77 \\
Increased personal competencies & 284 & 68.43 \\
Improved learning ability & 247 & 59.52 \\
Make new friends (social capital network) & 248 & 59.76 \\
\hline \hline
\end{tabular}

TABLE X: TOPICS OF INTEREST $(N=810)$

\begin{tabular}{ccccccc}
\hline \hline & \multicolumn{2}{c}{ Degree } & \multicolumn{2}{c}{ Short term } & \multicolumn{2}{c}{ Total } \\
\cline { 2 - 7 } Items & $n$ & $\%$ & $n$ & $\%$ & $n$ & $\%$ \\
\cline { 2 - 7 } & 216 & 26.67 & $\mathbf{3 4 8}$ & 42.96 & 564 & 69.63 \\
Tourism & $\mathbf{2 5 5}$ & 31.48 & 252 & 31.11 & 507 & 62.59 \\
Academic studies & 153 & 18.89 & 206 & 25.43 & 359 & 44.32 \\
Arts and culture & 174 & 21.48 & 201 & 24.81 & 375 & 46.30 \\
Shopping & 200 & 24.69 & 163 & 20.12 & 363 & 44.81 \\
Health and wellness & 149 & 18.40 & 140 & 17.28 & 289 & 35.68 \\
Educational issues & 118 & 14.57 & 139 & 17.16 & 257 & 31.73 \\
Societal issues & 193 & 23.83 & 117 & 14.44 & 310 & 38.27 \\
Entertainment news & 50 & 6.17 & 103 & 12.72 & 153 & 18.89 \\
Political issues & 126 & 15.56 & 64 & 7.90 & 190 & 23.46 \\
Sports events & 45 & 5.56 & 39 & 4.81 & 84 & 10.37 \\
International news & & & & & &
\end{tabular}

TABLE XI: PERCEPTION ON TAIWAN $(N=810)$

\begin{tabular}{|c|c|c|c|c|}
\hline \multirow{2}{*}{ Items } & \multicolumn{2}{|c|}{ Degree } & \multicolumn{2}{|c|}{ Short term } \\
\hline & Mean & $S D$ & Mean & $S D$ \\
\hline \multicolumn{5}{|l|}{ Taiwanese people in general } \\
\hline Empathy & 4.41 & 0.730 & 4.61 & 0.603 \\
\hline Customer service (shopping/stores) & 4.47 & 0.670 & 4.55 & 0.607 \\
\hline Basic courtesy & 4.36 & 0.760 & 4.50 & 0.566 \\
\hline Civic mindedness and law abiding & 4.25 & 0.730 & 4.48 & 0.648 \\
\hline Ecological awareness & 4.35 & 0.710 & 4.46 & 0.639 \\
\hline Sense of democracy & 4.03 & 0.890 & 4.19 & 0.726 \\
\hline Taiwanese acceptance of foreign culture & 3.70 & 0.940 & 3.93 & 0.845 \\
\hline Taiwanese internationalization & 2.76 & 1.260 & 3.23 & 1.077 \\
\hline Taiwanese understanding of China & 1.99 & 1.020 & 2.26 & 1.139 \\
\hline TOTAL & 3.81 & 0.857 & 4.02 & 0.761 \\
\hline \multicolumn{5}{|l|}{ Society } \\
\hline Cleanliness (Hygiene) & 3.97 & 0.760 & 4.31 & 0.656 \\
\hline Food and delicacies & 4.07 & 0.880 & 4.26 & 0.807 \\
\hline Internet freedom & 4.01 & 0.900 & 4.22 & 0.787 \\
\hline Sights and sceneries & 3.75 & 0.870 & 4.19 & 0.716 \\
\hline News media freedom & 3.75 & 1.120 & 4.11 & 0.890 \\
\hline Preservation of traditional cultures & 3.95 & 0.930 & 4.11 & 0.820 \\
\hline Transportation and livelihood & 3.32 & 1.210 & 3.75 & 1.057 \\
\hline TOTAL & 3.83 & 0.953 & 4.14 & 0.819 \\
\hline \multicolumn{5}{|l|}{ Academic } \\
\hline Campus environment & 3.83 & 0.930 & 4.33 & 0.732 \\
\hline Learning resources & 4.06 & 0.890 & 4.32 & 0.734 \\
\hline Value adding & 3.89 & 0.790 & 4.06 & 0.836 \\
\hline Learning atmosphere (seriousness) & 3.22 & 1.090 & 3.36 & 1.072 \\
\hline TOTAL & 3.75 & 0.925 & 4.02 & 0.844 \\
\hline
\end{tabular}

\section{E. Push-Pull Factors}

As for the gains (pull factors) of studying in Taiwan, Table XIV shows that students mentioned various issues with the understanding of Taiwan as the main advantage. One interesting gain is the notion of travel planning, students while studying in Taiwan tends to travel around the island. Furthermore, with the variety of travel options students spends a lot of time planning for their trips.

For the negative (push) factors, students mentioned the following: too many restrictions (part-time job, course of study), lack of opportunities to apply for Taiwan scholarship, misconception towards Mainland Chinese students, not much activities geared towards Mainland China (mostly focused on Western countries), and the need to help broadens the local students notion of Mainland Chinese students (positive issues).

TABLE XII: PERCEPTION ON LEARNING $(N=810)$

\begin{tabular}{ccccc}
\hline \hline & & & & \\
Items & Degree & Short term \\
& & & & \\
\cline { 2 - 5 } & Mean & $S D$ & Mean & $S D$ \\
\hline Library resources & $\mathbf{4 . 1 3}$ & 0.850 & $\mathbf{4 . 3 4}$ & 0.804 \\
Quality of faculty (professionalism) & 4.09 & 0.780 & $\mathbf{4 . 3 3}$ & 0.783 \\
Classroom environment & 3.91 & 0.800 & 4.16 & 0.790 \\
Educational technologies & 3.98 & 0.750 & 4.14 & 0.703 \\
Teaching pedagogy & 3.89 & 0.830 & 4.13 & 0.775 \\
Laboratory apparatus and equipment & 3.90 & 0.800 & 4.07 & 0.763 \\
Applicability of the courses & 3.74 & 0.880 & 4.05 & 0.794 \\
Quality of professional courses & 3.89 & 0.830 & 4.03 & 0.816 \\
Able to help students with special needs & 3.96 & 0.800 & 4.03 & 0.795 \\
Quality of general education & 3.70 & 0.860 & 4.00 & 0.797 \\
Able to discuss lessons with faculty & 3.80 & 0.840 & 3.95 & 0.889 \\
Course evaluations & 3.74 & 0.790 & 3.90 & 0.866 \\
Theoretical foundations of lessons & 3.74 & 0.820 & 3.80 & 0.764 \\
Discussions with local students & 3.82 & 0.940 & 3.63 & 1.014 \\
Internship opportunities & 3.37 & 0.980 & 3.59 & 0.981 \\
In classroom discussions & 3.25 & 1.050 & 3.51 & 1.051 \\
Taiwanese students' internationalization & 2.73 & 1.190 & 3.16 & 1.103 \\
Taiwanese students' learning motivation & 3.03 & 1.130 & 3.07 & 1.120 \\
Taiwanese students' learning attitudes & 3.02 & 1.120 & $\mathbf{2 . 9 8}$ & 1.180 \\
Students understanding of China & $\mathbf{2 . 1 6}$ & 1.110 & $\mathbf{2 . 4 0}$ & 1.145 \\
TOTAL & $\mathbf{3 . 5 9}$ & 0.908 & $\mathbf{3 . 7 6}$ & 0.897 \\
\hline \hline
\end{tabular}

TABLE XIII: PERCEPTION ON SCHOOL ADMINISTRATION $(N=810)$

\begin{tabular}{ccccc}
\hline \hline & \multicolumn{2}{c}{ Degree } & \multicolumn{2}{c}{ Short term } \\
\cline { 2 - 5 } Items & & & & \\
& Mean & $S D$ & Mean & $S D$ \\
& & & & \\
\hline Personnel (staff) service attitude & $\mathbf{4 . 2 6}$ & 0.740 & $\mathbf{4 . 3 3}$ & 0.762 \\
Campus diversity & 4.01 & 0.820 & 4.30 & 0.723 \\
Quality of arts and cultural activities & 4.10 & 0.790 & 4.30 & 0.752 \\
Quality of activities & 4.00 & 0.840 & 4.29 & 0.788 \\
Sports and recreational resources & 3.97 & 0.910 & 4.28 & 0.748 \\
Dormitory quality and cleanliness & $\mathbf{3 . 4 3}$ & 1.150 & 4.25 & 0.878 \\
Dormitory resources (eg: beds, facilities) & 3.81 & 0.960 & 4.22 & 0.825 \\
Personnel (staff) work effectiveness & 3.87 & 0.940 & 4.19 & 0.709 \\
Dormitory management (security) & 3.77 & 0.990 & 3.90 & 0.951 \\
Food (meal) services & 3.64 & 0.930 & 3.88 & 0.922 \\
Medical services & 3.53 & 0.980 & 3.71 & 0.910 \\
Counseling services & 3.63 & 0.820 & $\mathbf{3 . 7 0}$ & 0.767 \\
TOTAL & $\mathbf{3 . 8 4}$ & 0.906 & $\mathbf{4 . 1 1}$ & 0.811 \\
\hline
\end{tabular}

With regards to the overall experience of studying in Taiwan, Table XV shows that the participants from both degree and short-term program all noted positive experiences. Moreover, above average expectations are noted on issues such as the value for money and supports of local school 
administrations. Comparison with the degree seeking and short-term program students shows that the latter noted a much higher expectation rating than the former on most of the issues.

TABLE XIV: OVERALL STUDY GAINS IN TAIWAN $(N=810)$

\begin{tabular}{|c|c|c|c|c|c|c|}
\hline \multirow{2}{*}{ Items } & \multicolumn{2}{|c|}{ Degree } & \multicolumn{2}{|c|}{ Short term } & \multicolumn{2}{|c|}{ Total } \\
\hline & $n$ & $\%$ & $n$ & $\%$ & $n$ & $\%$ \\
\hline Understanding of Taiwan & 289 & 35.68 & 347 & 42.84 & 636 & 78.52 \\
\hline Respect for others (courtesy) & 206 & 25.43 & 274 & 33.83 & 480 & 59.26 \\
\hline Travel planning & 164 & 20.25 & 272 & 33.58 & 436 & 53.83 \\
\hline Independent & 229 & 28.27 & 252 & 31.11 & 481 & 59.38 \\
\hline Interpersonal communication & 195 & 24.07 & 234 & 28.89 & 429 & 52.96 \\
\hline Presentation skills & 175 & 21.60 & 198 & 24.44 & 373 & 46.05 \\
\hline Openness to new experience & 145 & 17.90 & 195 & 24.07 & 340 & 41.98 \\
\hline Cross-cultural adaptability & 180 & 22.22 & 191 & 23.58 & 371 & 45.80 \\
\hline Self-efficacy & 193 & 23.83 & 187 & 23.09 & 380 & 46.91 \\
\hline Creativity and innovation & 121 & 14.94 & 172 & 21.23 & 293 & 36.17 \\
\hline Group work & 153 & 18.89 & 150 & 18.52 & 303 & 37.41 \\
\hline Problem solving skills & 134 & 16.54 & 140 & 17.28 & 274 & 33.83 \\
\hline Leadership skills & 72 & 8.89 & 50 & 6.17 & 122 & 15.06 \\
\hline
\end{tabular}

TABLE XV: OVERALL EXPERIENCE IN TAIWAN $(N=810)$

\begin{tabular}{ccccc}
\hline \hline & \multicolumn{2}{c}{ Degree } & \multicolumn{2}{c}{ Short term } \\
\cline { 2 - 5 } Items & Mean & SD & Mean & SD \\
& & & & \\
\hline Encourage friends to study in Taiwan & 3.91 & 0.950 & $\mathbf{4 . 3 8}$ & 0.701 \\
Value for money & 4.03 & 0.830 & 4.35 & 0.695 \\
Support from local Taiwanese HEIs & $\mathbf{4 . 0 7}$ & 0.790 & 4.24 & 0.670 \\
Assistance in academic documents & 3.84 & 0.930 & 4.15 & 0.794 \\
Quality of relationship with dorm mates & $\mathbf{3 . 0 1}$ & 1.120 & 4.08 & 0.763 \\
Quality of discussions with local students & 3.99 & 0.820 & 4.04 & 0.799 \\
Ability to accomplish course related tasks & 4.02 & 0.770 & 4.03 & 0.823 \\
Quality of orientation upon arrival & 3.99 & 0.920 & 4.01 & 0.862 \\
Take on further studies in Taiwan & 3.67 & 1.110 & 4.00 & 0.938 \\
Teaching pedagogy & 3.85 & 0.810 & 3.94 & 0.816 \\
Rapport between classmates & 3.94 & 0.870 & 3.89 & 0.816 \\
Local social network (circle of friends) & 3.89 & 0.900 & 3.88 & 0.863 \\
Taiwanese students' creativity & 3.59 & 0.980 & 3.84 & 0.940 \\
Plans to work and stay in Taiwan & 3.44 & 1.220 & 3.84 & 0.984 \\
Special tourism activities for students & 3.91 & 0.980 & 3.75 & 1.062 \\
Airport pickup and sendoff services & 3.44 & 0.960 & 3.63 & 0.853 \\
Taiwanese students' idolatry in artists & 3.28 & 0.990 & 3.31 & 0.972 \\
Taiwanese students' sense of maturity & 4.06 & 0.840 & 3.24 & 1.083 \\
Taiwanese students' attitude in class & 3.14 & 1.090 & $\mathbf{2 . 9 8}$ & 1.240 \\
TOTAL & $\mathbf{3 . 7 4}$ & 0.941 & $\mathbf{3 . 8 7}$ & 0.878 \\
\hline \hline
\end{tabular}

In sum, results show that besides knowing the culture first hand, the mainland Chinese students' major pull factors are the opportunity to travel and experience life in Taiwan, various curriculum programs availability, numerous cultural related activities, shopping experiences, and healthy lifestyle. As for their perception on Taiwan, Chinese students prefer the warm, courteous, and helpful attitudes of Taiwanese people in general. One interesting finding is that almost all of the mainland Chinese students are in Taiwan by their own expense. Such finding is actually contrary to the previous practice with the western counterparts; wherein quite a number of international students are in Taiwan with scholarships.

\section{CONCLUSION}

The main objective of this study is to understand the various pull factors and implications with regards to the mainland Chinese students studying in Taiwan. It is noted that participating in a study abroad program can lead to various insights and built-up necessary skills to interact with people who are different. More so, with the current emphasis on doing businesses in China, understanding how mainland Chinese students react in a new environment is a step towards better future cooperation. In essence, this study shall provide new insights in the paradigm shifts from internationalization into a cross-straitization of higher education institutions in Taiwan.

\section{REFERENCES}

[1] M. C. Chin and G. S. Ching, "Trends and indicators of Taiwan's higher education internationalization," The Asia-Pacific Education Researcher, vol. 18, pp. 185-203, 2009.

[2] C. P. Chou, A. Roberts, and G. S. Ching, "A study on the international students' perception and norms in Taiwan," International Journal of Research Studies in Education, vol. 1, pp. 71-84, 2012.

[3] H. Zhao. (July 2012). Taiwan-mainland economic cooperation framework agreement. [Online]. Available: http://www.chinapost.com.tw/taiwan/china-taiwan-relations/2011/01/ 05/286406/First-mainland.htm

[4] B. B. Ji. (July 2012). Graduating across the Taiwan Straits. [Online]. Available: http://www.globaltimes.cn/content/717512.shtml.

[5] Formosa. (July 2012). President Ma pledges to form committee to permit more Chinese students. [Online]. Available: http://englishnews.ftv.com.tw/read.aspx?sno=8B9EA11A3C538A446 7AAA72A3657AC15

[6] C. P. Chou and G. S. Ching, Taiwan Education at the crossroad: When Globalization Meets Localization, New York: Palgrave Macmillan, 2012.

[7] The China Post. (July 2012). First mainland students to enroll in September. [Online]. Available: http://www.chinapost.com.tw/taiwan/china-taiwan-relations/2011/01/ 05/286406/First-mainland.htm.

[8] B. McMurtrie. (July 2012). International enrollments at US colleges grow but still rely on China. [Online]. Available: http://chronicle.com/article/International-Enrollments/129747/.

[9] G. Kuo. (July 2012). Foreign tertiary student numbers rise in Taiwan. [Online]. http://www.taiwantoday.tw/ct.asp?xItem=193074\&ctNode=445.

[10] K. Mok and T. Tan, Globalization and Marketization in Education: A Comparative Analysis of Hong Kong and Singapore, UK: Edward Elgar Publishers, 2004.

[11] L. Sirowy and A. Inkeles, "University-level student exchanges: The U.S. role in global perspective," in Foreign Student Flows: Their Significance for American Higher Education, E. G. Barber, Ed., New York: Institute of International Education, 1985.

[12] G. Fry, "The economic and political impact of study abroad," Comparative Education Review, vol. 28, pp. 203-220, 1984.

[13] W. K. Cummings, "Global trends in international study," in International Investment in Human Capital, G. Craufurd, Ed., New York: Institute of International Education, 1993.

[14] V. B. Agarwal and D. R. Winkler, "Foreign demand for United States higher education: A study of developing countries in the eastern hemisphere," Economic Development and Cultural Change, vol. 33, pp. 623-644, 1985.

[15] P. G. Altbach, Comparative Higher Education: Knowledge, the University and Development, Chestnut Hill: Center for International Higher Education, Boston College and Ablex Publishing Corporation, 1997.

[16] A. Roberts, C. P. Chou, and G. S. Ching, "Contemporary trends in East Asian higher education: Dispositions of international students in a Taiwan university," Higher Education, vol. 59, pp. 149-166, 2010.

[17] T. Mazzarol, "Critical success factors for international education marketing," International Journal of Educational Management, vol. 12, pp. $163-175,1998$

[18] L. Cohen, L. Manion, and K. Morrison, Research methods in education, New York: Routledge, 2007.

[19] E. G. Carmines and R. A. Zeller, Reliability and Viability Assessment, Thousand Oaks, CA: Sage, 1991.

[20] J. C. Nunnally, Introduction to Psychological Measurement, New York: McGraw-Hill, 1970. 
[21] M. C. Chin and G. S. Ching, "Apple and oranges: Comparison of Taiwan higher education institutions' internationalization," International Journal of Research Studies in Education, vol. 1, pp. 3-22, 2012.



Chuing Prudence Chou received her $\mathrm{PhD}$ in comparative and international education from the University of California, Los Angeles, and is a professor in the Department of Education at National Cheng-chi University, Taipei, Taiwan. Chou's new book, Taiwan Education at the Crossroad: When Globalization Meets Localization (New York: Palgrave Macmillan), is expected to serve as one of the very few pioneering works detailing the multi-facet forces that Taiwan education has encountered in complicated global, local, and cross-strai relationships between China and Taiwan. She also proposes a new paradigm which attempts to promote mutual understanding and peace among nations of conflicts via educational exchanges.

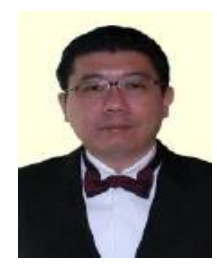

Gregory S. Ching received his $\mathrm{PhD}$ in education from the National ChengChi University, Taiwan, and is currently an assistant professor at the Graduate School of Educational Leadership and Development in Fu Jen Catholic University, Taiwan. His research interest includes technology and education, globalization, higher education issues, international student mobility, and student engagement. 